\title{
LUT
}

University

Making Sense of Culture in Management: Qualitative Sensemaking Approach in Explaining Cross-Cultural Business Networking

Torkkeli Lasse, Ivanova-Gongne Maria

This is a Author's accepted manuscript (AAM) version of a publication published by SAGE Publications

in SAGE Research Methods Cases

DOI: $10.4135 / 9781529724608$

Copyright of the original publication: (c) 2020 SAGE Publications

Please cite the publication as follows:

Torkkeli, L., Ivanova-Gongne, M. (2020). Making sense of culture in management: Qualitative sensemaking approach in explaining cross-cultural business networking. In: SAGE Research Methods Cases. DOI: 10.4135/9781529724608

This is a parallel published version of an original publication. This version can differ from the original published article. 
See discussions, stats, and author profiles for this publication at: https://www.researchgate.net/publication/338742266

\section{Making Sense of Culture in Management: Qualitative Sensemaking Approach in Explaining Cross-Cultural Business Networking}

Book · January 2020

DOI: $10.4135 / 9781529724608$

\section{CITATIONS}

0

2 authors:

Lasse Torkkeli

Lappeenranta - Lahti University of Technology LUT

46 PUBLICATIONS 132 CITATIONS

SEE PROFILE
READS

20

Maria Ivanova-Gongne

Åbo Akademi University

22 PUBLICATIONS 104 CITATIONS

SEE PROFILE

Some of the authors of this publication are also working on these related projects:

Finnish-Russian business relationships: An intercultural and individual perspective View project

Project Boosting the Internationalization of Cleantech SMES (BICS) View project 
Case Title

Making Sense of Culture in Management: Qualitative Sensemaking Approach in Explaining Cross-Cultural Business Networking

Discipline

Business and Management [D12]

Academic Level of intended readership

Advanced Undergraduate

Dr. Lasse Torkkeli is an Adjunct Professor of International Business in the Turku School of Economics at the University of Turku, and an Associate Professor at the School of Business and Management at LUT University at Lappeenranta, Finland. Torkkeli's research interests are in the international entrepreneurship and international business domains, and include SME internationalization, business networks, organizational capabilities and competencies. He has previously published in the International Marketing Review, Journal of International Entrepreneurship and in the European Management Journal, among others.

Dr. Maria Ivanova-Gongne is a University Teacher in International Marketing at Åbo Akademi University. Her research interests include business-to-business marketing management, particularly the aspects of business interaction and communication, managerial sensemaking and culture in international business-to-business relationships and networks. Ivanova-Gongne has published her research in international top journals such as Industrial Marketing Management, Scandinavian Journal of Management, European Management Journal and Journal of Business and Industrial Marketing.

Published Articles 
Ivanova-Gongne, M., \& Torkkeli, L. (2018). No manager is an island: culture in sensemaking of business networking. Journal of Business \& Industrial Marketing, 33(5), 638-650.

\begin{abstract}
[Insert here: Maximum of 250 words]

Business today is increasingly global, requiring entrepreneurs and managers aiming to internationalize their enterprises to develop and foster business network relationships. Therefore, business researchers have often focused on the role that networks have in business relationships in general, and those occurring in international business and entrepreneurship in particular. However, the cultural background of managers may impact the ways in which they make sense of business networking, an area the research has paid less attention to. In this study, we applied a qualitative methodology through the sensemaking approach on managers in mutual business relationship dyads.
\end{abstract}

The research context is Finnish and Russian managers of internationally operating enterprises. We sought to illustrate how they make sense of their mutual business relationship, and how their cultural background can impact that understanding. The study is based on a long-term research project where the researchers aim to explain sensemaking in small-and medium-sized enterprises (SMEs) in different cultural contexts.

Readers will learn how the sensemaking approach can be used to capture cultural understanding of business concepts. In addition, they will learn how to structure the interviews, how to code the data and what challenges can arise in interpreting the data. 


\section{Learning Outcomes}

By the end of this case, students should be able to:

- Evaluate and interpret how the cultural background of the research informant and the researcher can impact findings of a research.

- Choose and defend the choice of research methodology for data coding and interpretation.

- Select and design qualitative research process applying the sensemaking narrative approach.

- Justify the reasons for conducting cross-cultural research, particularly in Russia and Finland.

\section{Case Study}

\section{Project Overview and Context}

Business networks and networking behavior of businesspersons is a topic that has both research and practical implications. Yet how people engage with each other across cultures and which are the acceptable and expected behaviors in business interaction and network-building is a complex topic to make sense of. For instance, in order for an entrepreneur or a manager born and raised in Western Europe to do business in China, (s)he should be aware of the cultural concept of "guanxi" that determines the ways in which business networks in China are formed and how the Chinese engage in networking in order to do business in their home country (for more information see e.g. Michalova and Worm, 2003). In order to do the same in Russia, 
understanding the Russian culture and culture-specific concepts that relate to networking - for example the concept of "blat" can be necessary. However, there has been a distinct lack of knowledge on what exactly happens when managers whose cultural background and companies originate from different markets actually start to develop a business relationship and especially on how they make sense of the networking process. Typical questions they may then asks themselves can be, for instance: "How much of a personal relationship should I establish with my foreign business counterpart before we can actually start trading?"; and "Do I need to develop a personal relationship with the foreign business counterpart before our companies can start doing business together, and if so, to what extent do I need to?"

In order to find out answers to these questions, in this research project we sought to understand and explain the ways in which managers from different cultural backgrounds make sense of business networking. We applied qualitative sensemaking approach to study both counterparts of business relationship dyads and to do so accounting for both developed and emerging-market environments. As such, a qualitative interview is inherently a sensemaking process, the outcome of which is a narrative from the point of view of the interviewee (Ivanova-Gongne \& Törnroos, 2017). The key properties of sensemaking include amongst all the "enactive of the environment" and "retrospective" elements. Enactive of the environment component of sensemaking indicates that making sense is influenced by the environment/context within which the individual acts and makes sense (Helms Mills et al., 2010). Retrospective element of sensemaking means that interviewees largely rely on past experience to interpret the event/phenomena. Furthermore, when making sense of the events that happened to them, individuals apply certain cultural schemas, which "are 
cognitive structures that constitute knowledge and serve as resources for ascribing meaning and assist individuals in making sense of various situations" (IvanovaGongne, 2015, p. 610). These cultural schemas reflect both the "retrospective" and "enactive of the environment" function of sensemaking, since they are ingrained in the individual's cognition through past experiences and contain cultural knowledge within a specific environment. Thereby applying a sensemaking approach is particularly helpful in understanding the intercultural aspect of international business.

In applying the sensemaking approach, we focused on the Finnish-Russian business relationships, which provide a suitable context for conceptualization of business networking cross-culturally. We could expect to find dissimilarities in sensemaking of networking between managers originating from these countries, due to the fact that Finnish business relationships are characterized by formality and concentrating on the goals of the organization, rather than the individual (Konsti-Laakso et al., 2012). Conversely, in Russia networks have been found to be determined by cultural heritage and characterized by culturally-specific concepts such as "blat" (Ledeneva and Ledeneva, 1998; Michailova and Worm, 2003). "Blat" has been traditionally defined as "the use of personal networks for obtaining goods and services in short supply and for circumventing formal procedures” (Ledeneva, 2009, p. 257). In general, such concepts highlights the importance of personal networks both in business and private life. Moreover, the comparatively dynamic business environment in Russia has been linked to more conflicts in business relationship (Radaev, 2013), while in the Finnish business culture, maintaining consensus is of high priority in general (Lämsä, 2010). We were interested in exploring further how managers originating from these distinct environments for doing business in general, and on networking in particular, can and do form, develop and manage mutual business relationships. 
We noticed that very little was known about how people make sense of their business relationships in such dyadic relationships in general: most research on these topics adopted a traditional case study approach, which tends to take the organization as the unit of analysis and focus on people and processes within that organization (see Eisenhardt, 1989; Yin, 2009). However, such traditional case study methodological approach can be less suitable in some circumstances, for instance when the aim is to study interactions, relationships between different organizations and individual, or business networks. In such cases, it is necessary to examine and interview people from both sides of the relationship dyad, which would truly help in bringing out how people make sense of a common, single phenomenon - a specific business relationship. Moreover, we noticed that studies that did try to highlight the culturally specific concepts of networking, such as on "blat" and "guanxi", did not look at the relationship dyads either. These were the areas we wanted to clarify: How do managers with different cultural backgrounds make sense of their mutual business relationship and how do they see each other from the networking point of view?

\section{Research Design}

Since our study was an exploratory look into individual sensemaking, we determined that, in line with Yin (2009), we should apply qualitative research methods to obtain information that would be in-depth and detailed enough to draw conclusions on conceptualization of business terms. For the specific methodological approach, we considered the aims and the conceptual background to fit very well to the narrative 
approach (Boje, 2001; Brown, 2006) as it has been found to be particularly applicable in studying sensemaking in business relationships in general. (Brown et al., 2008).

Since we were about to collect data from people with very different cultural backgrounds, different native languages and from differing country of origins of their respective companies, we determined that adopting a semi-structured interview approach would be a start. We realized that we would in effect need to ascertain and interpret culturally embedded narratives that could be expected to contain significant amounts of tacit knowledge on the behavior of the interviewees. This raised first the issue of how we could make sure that this tacit knowledge would be shared between the interviewee and the interviewer, so that the resulting interpretation of their conceptualization would be accurate.

Since we personally have a Finnish and Russian cultural background respectively, the obvious solution to this was that we would look into Finnish-Russian context and each of us would be responsible for interviewing managers in our respective home country. In doing so, we could ensure that the interviews could be conducted in the native language of the managers, an important distinction since many cultural concepts (such as blat), idioms and proverbs are not easily translated in English. We sought to obtain narratives based on the interviewees' cultural background and, as Lincoln and Guba (1985) have pointed out, the credibility of such narratives can be best ensured if the interviewers, meaning here us as researchers, have been engaged longer in learning about the culture. In making this decision to share the interviewing duties so that each of us would interview the managers with similar cultural backgrounds, and in the respective native languages, we realized of course that we 
would need to translate the interview transcriptions to English. That would be needed in order to report the study jointly, to compare the responses from each country, and to publish the results in an English research journal. However, the fact that we as researchers have Finnish and Russian cultural backgrounds, meant that each of us had extensive personal knowledge of our own cultures and could thus best decipher culturally specific references in the interviews, in order to obtain richer data and to make their analysis more credible.

\section{Research Practicalities}

We conducted the study without a larger formal research team, instead choosing to pool our own ideas and resources as a Finnish and Russian business researcher. First, we needed to obtain information on suitable dyadic business relationships between Finnish and Russian companies. As there is no public database available that would list such relationships, we had to start in one of the countries by looking for companies that would conduct business - that would have direct business relationship - with a company in the other country. In doing so, we also had to ensure that the cultural background of the manager was the same as the home country of the company. This meant that we would have to look for Finnish companies with Finnish managers that would have a business relationship with a Russian company with a Russian manager.

We started off by contacting the Finnish-Russian chamber of commerce in order to obtain information of Finnish member companies. We presumed that a Finnish company that would be a member of the chamber of commerce would at the very 
least have interest in doing business in Russian markets and would in most cases actually do business in Russia. We delimited the search to those companies in industrial buyer-supplier (business-to-business) relationships, due to the fact that companies operating mainly in consumer markets would be expected to not have a manager at the target market with whom a long-term dyadic business relationship would have been formed. We selected the mechanical-engineering industry because most companies in the mechanical engineering business in Finland tend to be highly specialized and thus engaging in business networks outside their domestic border are often a necessity to them. Another fact is that much of the existing research on business networking and networks has been conducted in similar environments, thus we expected to better be able to compare and contrast our findings with earlier studies.

We consequently e-mailed the 10 most promising Finnish companies a request in Finnish language to participate in the study. In the e-mail we made it clear that in order to be suitable for the study, the company would have to have business in Russia; they would need to have one most important business relationship with a company in the target market they could be interviewed about; and that a Finnish researcher would arrive to the premises and seek to interview the Finnish manager in the native language of both. After the initial e-mail and subsequent phone call to set up the interviews, three of the contacted companies agreed to participate in the study.

Altogether, we conducted seven semi-structured interviews, by using an interview guide to steer the interviews. In addition to asking the questions from the interview guide, we encouraged the interviewees specifically to share stories about the 
development of their business relationships, particularly through narratives about what they considered the key interactive events of the relationships. The interview guide thus was used as an initial trigger to facilitate the storytelling of the interviewees, rather than a strictly followed protocol. Interviews were conducted in Finnish and Russian respectively, and lasted ca. $9 \mathrm{~h}$ in total, varying between 60 to 150 minutes. We sought to interpret the narratives arising in the interviews through our own cultural and language lenses, as stories told in the interviewees' native language tend more emotionally intense and thus provide richer data (Pavlenko, 2007).

During the Finnish interviews, we also obtained the up-to-date contact information of the partner company in Russia, and the Russian manager therein with which the business relationship existed. We exchanged this contact information between us and then the Russian researcher contacted the Russian managers in the companies, all of which were from the St. Petersburg area. We presumed that, once we approached the Russian contacts by describing that we had already been in contact with their Finnish partner in Finland who had agreed to participate, we could expect to see more initial trust and willingness to also participate from the Russian managers. This was indeed the case, as all three partner companies in Russia agreed to participate, and we were able to interview the managers "on the other side of the dyad" in Russian soon after. 


\section{Method in Action}

By travelling to the premises of the companies ourselves, we aimed for the interviews to provide an environment where the managers would be comfortable in discussing their experiences on the business relationships. We deemed this crucial, as some of the topics of discussion, such as asking the managers to describe how they understood "business network" and "business networking" in Finnish and Russian contexts, could be considered quite philosophical and unusual for a manager to consider as part of their daily work. Perhaps thanks to this, and the fact that we left these more challenging conceptual questions towards the end of the interview guide, in most cases the narratives and descriptions we gained when proposing these questions where quite sufficient.

However, from the start we did notice a stark difference between the responding styles of the Finnish and Russian managers: The former provided only scant culturally specific (Finnish) idioms, proverbs or other similar culturally specific artifacts that would need to be interpreted. This was in stark contrast with the Russian managers, who used a large amount of Russian proverbs, sayings and culturally specific terms when describing their business relationship activities and how they understood business networking to occur throughout their relationship.

Similarly, the Finnish managers repeatedly retreated to describing networking activities and goals from the point of view of the goals of their company, rather than their own experience as an individual. Again, this was contrasted by the Russian 
managers, who described their business relationship and networking almost squarely by providing narratives about the personal point of view.

\section{Practical Lessons Learned}

By applying this research method in the study, we were able to ascertain not only the similarities in dyadic business relationships, but even more importantly, to gain many unexpected insights that then guided our interpretation of the data. We did not anticipate, for instance, that it would be so challenging to obtain culturally-specific conceptualization from the Finnish managers. Yet time and again they would, even when inquired from repeatedly to consider cultural specifics, retreat to discussing the goals of their company in business networking and in their narratives mainly use the business terminology on business networking that prevails most of Western Europe (and it thus not specific to the Finnish culture).

However, we were able to turn these unexpected "omissions" to success by looking more deeply into the possible reasons for this lack of cultural-specific narratives and concepts. While we consider it possible that in an interview situation also the personal style of the interviewee and the structure of the interview guide may impact the obtained data, including three separate dyads into the data collection ensured that the interviewees were also different and thus the dynamic of the situation distinct each time. Moreover, we made revisions to the interview guide from the first to the second to the third dyad, seeking to obtain more culturally specific data. However, in all 
cases the results were similar, thus we concluded that it was not the guide or the interview dynamic itself that would have caused the results.

On the other hand, the openness of Russian interviewees contradicted the general view in previous literature on its restricted nature (Michailova and Liuhto, 2001; Abrahamsen and Håkansson, 2015). The researcher taking care of the Russian interviews, however, had to execute several special techniques in order to obtain a more in-depth interview from the Russian managers. Trust from the interviewees was initially higher due to contacting them through mutual connections, i.e. the Finnish firms. Furthermore, a more extensive and personal small talk before going on to the interview questions was required in order to enhance trust further. Finally, the researcher being of a female gender was advantageous in this particular situation. Previous research highlights that male interviewees strive to show and preserve their masculinity and be in control of the situation in an interview setting (Schwalbe and Wolkomir, 2003). Russian heavy industry is highly male dominated and gender stereotypes are still widespread. Thus, a female-male interview setting may allow them to be more open and feel in control of the situation, in contrast to a purely malemale interaction.

In a similar vein to Russian interviews, when starting to contact the Finnish companies for interviews, we soon realized that the gender and age profile of the managers would turn out to be quite homogenous: All of the informants, also in the contacted firms that were not included eventually into the dyads, were middle-aged males. We surmise that this is due to the chosen industry context (mechanical engineering), which in Finland tends to be quite male-dominated area of business. 
While at the business management level such large gender differences might not be expected, we did notice that in almost without exception, in the contacted companies the manager responsible for the international business relationship had an engineering rather than business education.

Individual cognition and sensemaking, in particular the application of certain schemas to understanding the events can also be to an extent gender- and age-specific, but in our analysis we did not find any evidence suggesting that the results were limited in this sense. Thus, we recommend that future research projects can rely on sensemaking approach through similar qualitative methodology. However, when applying such an approach a researcher or student should be knowledgeable of culturally specifics ways to approach an interview in order to obtain more in-depth results.

\section{Conclusions}

In conclusion, this study further helps to emphasize the point that the choice of a given research methodology will naturally delimit the ways in which data are collected and analyzed, and how the results are interpreted. At the broad level, qualitative inquiry such as case study and sensemaking approaches are best suited for in-depth inquiry on processes, phenomena and understanding individual cognition, which quantitative approaches by their nature tend to lack. Conversely, for generalizability of the results gained from empirical inquiry, larger samples provide a more rigorous basis. One could argue that a major limitation of this study derived 
from its phenomenological nature, which does not by itself necessarily provide clear prescriptions or pictures of the "mind of the Finnish (or Russian) manager.

We further note that such a generalizability may not even be possible; after all, we are all individuals with unique backgrounds. The question as to what it is exactly that makes a manager (or a researcher) "of Finnish (or Russian) cultural background" is not easily reconciled: For instance, would a Finnish manager that has completed his college studies in Russia, or worked and lived in Russia for five years, be considered "as Finnish" as a Finnish manager who has never been to Russia? Would (s)he make sense of business networking distinctly from a manager with the same nationality and ethnicity, yet one without any personal experience of working within the Russian business culture? These are questions that arose to us the most as we finished reporting on the results of this study and reflected back at them personally.

In sum, we conclude that a cultural sensemaking approach can and should be used more prevalently in research looking to illustrate how culture affects business in general, and business network and relationship development in particular. Future research could also look more closely to describe the differences in managerial sensemaking of business networking in other developing countries, which would allow for a more generalizable "Eastern" perspective on this phenomenon. 


\section{Exercises and Discussion Questions}

1. Why would a researcher choose to apply sensemaking approach to study businesses and managers? What are the strengths and weaknesses of taking such an approach to begin with?

2. What steps can a researcher take in order to ensure the credibility of a cross-cultural research applying a sensemaking approach?

3. What impact could culture have on conducting an interview oriented at understanding the sensemaking logic of a manager and how should you approach an analysis of such an interview?

4. Imagine you are tasked with interviewing a Russian middle-age male top-manager. What should you consider before and during the interview?

5. What is the role of language in conducting research across cultures and how to handle challenges related to language in a research?

6. How would you account for the gender of the researcher and the informant when collecting data in qualitative cross-cultural research?

\section{Further Reading}

1. Weick, K. E. (1995). Sensemaking in organizations (Vol. 3). Sage.

2. Puffer, S. M., \& McCarthy, D. J. (2011). Two decades of Russian business and management research: An institutional theory perspective. Academy of Management Perspectives, 25(2), 21-36.

3. Lovell, S., Ledeneva, A. V., \& Rogachevskiı̆, A. B. (2000). Bribery and blat in Russia: Negotiating reciprocity from the Middle Ages to the 1990s.

4. Liamputtong, P. (2010). Performing qualitative cross-cultural research. Cambridge University Press.

5. Temple, B., \& Young, A. (2004). Qualitative research and translation dilemmas. Qualitative research, 4(2), 161-178. 


\section{Web Resources}

1. Finnish-Russian Chamber of Commerce Website: https://www.svkk.fi/svkk/inenglish/

2. Finnish Business Culture Website: https://businessculture.org/northerneurope/finland/

\section{References}

Abrahamsen, M. H., \& Håkansson, H. (2015). Caught in the middle: Buying from markets and selling to networks. Industrial Marketing Management, 49, 4-14.

Boje, M. (2001). Narrative methods for organizational and communication research. London: Sage.

Brown, A. D. (2006). A narrative approach to collective identities. Journal of Management Studies, 43(4), 731-753.

Brown, A. D., Stacey, P., \& Nandhakumar, J. (2008). Making sense of sensemaking narratives. Human Relations, 61(8), 1035-1062.

Eisenhardt, K. M. (1989). Building theories from case study research. Academy of management review, 14(4), 532-550. 
Helms Mills, J., Thurlow, A., \& Mills, A. J. (2010). Making sense of sensemaking: the critical sensemaking approach. Qualitative Research in Organizations and Management: An International Journal, 5(2), 182-195.

Ivanova-Gongne, M. (2015). Culture in business relationship interaction: An individual perspective. Journal of Business and Industrial Marketing, 30(5), 608-615.

Ivanova-Gongne, M. \& Törnroos, J-Å. (2017). Understanding cultural sensemaking of business interaction: A research model. Scandinavian Journal of Management, 33(2), 102112.

Konsti-Laakso, S., Pihkala, T., \& Kraus, S. (2012). Facilitating SME innovation capability through business networking. Creativity and Innovation Management, 21(1), 93-105.

Ledeneva, A. C., \& Ledeneva, A. V. (1998). Russia's economy of favours: Blat, networking and informal exchange (Vol. 102). Cambridge University Press.

Lincoln, Y. S., \& Guba, E. G. (1985). Naturalistic Inquiry (Vol. 75). Sage Publications.

Lämsä, T. (2010). Leadership styles and decision-making in Finnish and Swedish organizations. Review of International Comparative Management, 11(1), 139-149.

Michailova, S., \& Liuhto, K. (2001). Organisation and management research in transition economies: Towards improved research methodologies. Journal of East-West Business, 6(3), $7-46$. 
Michailova, S., \& Worm, V. (2003). Personal Networking in Russia and China:: Blat and Guanxi. European Management Journal, 21(4), 509-519.

Pavlenko, A. (2007). Autobiographic narratives as data in applied linguistics. Applied Linguistics, 28(2), 163-188.

Radaev, V. (2013). Market power and relational conflicts in Russian retailing. Journal of Business \& Industrial Marketing, 28(3), 167-177.

Schwalbe, M. L., \& Wolkomir, M. (2003). Interviewing men. In J. Holstein, \& J. F. Gubrium (Eds.), Inside interviewing: New lenses, new concerns (pp. 55-72). Thousand Oaks, CA: SAGE.

Yin, R. K. (2009). Case study research and applications: Design and methods. Sage Publications. 